\title{
Tooth Infection, CTCAE
}

National Cancer Institute

\section{Source}

National Cancer Institute. Tooth Infection, CT CAE. NCI Thesaurus. Code C143878.

A disorder characterized by an infectious process involving a tooth. 